OPEN ACCESS

Edited by:

Matthias Brand,

University of Duisburg-Essen,

Germany

Reviewed by:

Katie Moraes de Almondes,

Federal University of Rio Grande do

Norte, Brazil

Hadj Boumediene Meziane,

University of Lausanne, Switzerland

*Correspondence:

Aviv M. Weinstein

avivwe@ariel.ac.il,

avivweinstein@yahoo.com

Specialty section:

This article was submitted

to Psychopathology,

a section of the journal

Frontiers in Psychiatry

Received: 27 June 2017 Accepted: 12 September 2017 Published: 29 September 2017

Citation:

Weinstein AM (2017) An Update Overview on Brain Imaging Studies

of Internet Gaming Disorder.

Front. Psychiatry 8:185.

doi: 10.3389/fpsyt.2017.00185

\section{An Update Overview on Brain Imaging Studies of Internet Gaming Disorder}

\author{
Aviv M. Weinstein* \\ Department of Behavioral Science, Ariel University, Ariel, Israel
}

There are a growing number of studies on structural and functional brain mechanisms underlying Internet gaming disorder (IGD). Recent functional magnetic resonance imaging studies showed that IGD adolescents and adults had reduced gray matter volume in regions associated with attention motor coordination executive function and perception. Adolescents with IGD showed lower white matter (WM) integrity measures in several brain regions that are involved in decision-making, behavioral inhibition, and emotional regulation. IGD adolescents had also disruption in the functional connectivity in areas responsible for learning memory and executive function, processing of auditory, visual, and somatosensory stimuli and relay of sensory and motor signals. IGD adolescents also had decreased functional connectivity of PFC-striatal circuits, increased risk-taking choices, and impaired ability to control their impulses similar to other impulse control disorders. Recent studies indicated that altered executive control mechanisms in attention deficit hyperactivity disorder (ADHD) would be a predisposition for developing IGD. Finally, patients with IGD have also shown an increased functional connectivity of several executive control brain regions that may related to comorbidity with ADHD and depression. The behavioral addiction model argues that IGD shows the features of excessive use despite adverse consequences, withdrawal phenomena, and tolerance that characterize substance use disorders. The evidence supports the behavioral addiction model of IGD by showing structural and functional changes in the mechanisms of reward and craving (but not withdrawal) in IGD. Future studies need to investigate WM density and functional connectivity in IGD in order to validate these findings. Furthermore, more research is required about the similarity in neurochemical and neurocognitive brain circuits in IGD and comorbid conditions such as ADHD and depression.

Keywords: Internet gaming disorder, brain imaging, functional magnetic resonance imaging, dopamine, reward

\section{INTRODUCTION}

\section{The Diagnosis and Brain Imaging of Internet Gaming Disorder (IGD)}

Internet gaming disorder involves excessive or poorly controlled preoccupations, urges, or behaviors regarding computer and videogame play that lead to impairment or distress (1). The behavioral addiction model argues that IGD shows the features of excessive use despite adverse consequences, withdrawal phenomena, and tolerance that characterize substance use disorders. There is a debate 
whether IGD is the best clinical term for diagnosing Internet addiction, for example, Young argued that IGD is a loss of control over gaming $(2,3)$ and others have suggested that it is an impulse control disorder (4) or a part of the obsessive-compulsive disorder (5). In the fifth edition of the Diagnostic and Statistical Manual of Mental Disorders (6), IGD is identified in Section "Brain Activation" as a condition warranting further clinical research and experience before it might be considered for inclusion as a formal disorder. Previous reviews have described brainimaging studies in IGD (7-12). In view of the rapid developments in brain research in IGD, particularly in adolescents, this review will summarize these studies and it will describe the gaps in our knowledge on brain imaging of IGD and bring them up to date to April 2017.

In PubMed, a search was conducted using the search terms "Internet addiction," "Internet Gaming Disorder," and "Pathological Internet use," each of which was combined with each of the terms "brain imaging," or "fMRI" or "PET" or "resting state" or "qualitative EEG" using the conjunction "AND." Each term was required to be present in the "Title/Abstract" of the article. The search was further limited by "English" as the publication language and Publication Date from 2008 to April 2017. The only studies that were selected for the review were original research articles that were published in peer-reviewed journals. The search has yielded eligible 98 studies of which 76 were selected including 23 studies of the resting state, 18 studies of functional connectivity, 27 activation studies, and 8 studies of pharmacology. As a general caution, throughout this review, in making group comparisons, there are reported differences between IGD group and control groups but these differences do not imply a causal role of IGD. Group differences may reflect predisposing factors rather than decreases due to IGD.

\section{Brain Imaging Studies of the Resting State in IGD}

Excessive Internet game use was associated with abnormal resting state activity in the brain regions that are responsible for impulse control, reward processing, and somatic representation of previous experiences (13). Adolescents with IGD also showed higher global cerebral blood flow in areas that are important for learning and memory (amygdala/hippocampus), conscious urges to use drugs (insula) executive function and inhibition (14). Individuals with IGD showed enhanced regional homogeneity ( $\mathrm{ReHo}$ ) in brain regions that relate with sensory-motor coordination (15, 16) and decreased ReHo in brain regions that are responsible for visual and auditory functions (15). The synchronization among these regions and the frontal lobe supports the evidence for enhancement of reward pathways (17). Both IGD and alcohol use disorder (AUD) patients had increased ReHo in the posterior cingulate cortex (PCC) an area associated with attention, future plans, and retrieval of autobiographical memories, whereas only IGD patients had decreased ReHo in the superior temporal gyrus an area associated with auditory processing and language (18). Scores on Internet addiction severity positively correlated with ReHo in the medial frontal cortex, precuneus/PCC, and left inferior temporal cortex (ITC) among participants with IGD
(18). A further clarification as to the difference between IGD and AUD is provided by a recent study on resting-state quantitative electroencephalography (QEEG) patterns associated with IGD and AUD (19). The study showed that lower absolute beta power can be used as a potential trait marker of IGD whereas higher absolute power in the delta band may be a susceptibility marker for AUD. This study clarifies the unique characteristics of IGD as a behavioral addiction, which is distinct from AUD, by providing neurophysiological evidence. In conclusion, studies of the resting state provide preliminary evidence for cognitive function in IGD but apart from a single study (18) they cannot provide evidence as to the development of IGD. The structural changes to brain regions that are involved in the function and maintenance of IGD need further corroboration before any conclusions are drawn.

\section{Studies on the Brain's Gray Matter Volume and White Matter (WM) Density}

Early studies showed higher left striatal gray matter volume in IGD participants in functional magnetic resonance imaging (fMRI) and these measures negatively correlated with deliberation time on the Cambridge Gambling Task (20). This study has used a decision-making task that can help clarify the relationships between brain function, i.e., decision-making and structural changes in reward centers in the brain. Participants with IGD had also lower gray matter density (GMD) in areas involved in urges and the regulation of emotional behavior but no causality can be inferred from the results of this study (21). Progamers showed increased gray matter volumes of areas associated with attention and sensory-motor coordination (22). Studies also found lower WM density measures in several brain regions [orbitofrontal cortex (OFC), corpus callosum, cingulate, inferior frontal-occipital fasciculus, and corona radiation, internal, and external capsules] in adolescents with IGD (23). Participants with IGD also showed higher WM density in the thalamus and left PCC and higher WM density in the thalamus was associated with greater severity of IGD (24). Participants with IGD showed decreased gray matter volume in frontal brain regions and reduced WM in the parahippocampal gyrus and the limb of the internal capsule (25). This study showed an association between gray matter atrophy and WM density with length of time of play enabling to assess effects of play on the brain's WM atrophy. Gray matter atrophy was reported in areas involved in cognitive and motor control and reduced WM density in areas involved in cognitive planning and control in IGD (26). Finally, IGD participants had lower GMD in brain regions that are involved in decision-making, behavioral inhibition and emotional regulation and reduced WM density in the inferior frontal gyrus, insula, amygdala, and anterior cingulate (27). In conclusion, these studies indicate preliminary findings of structural changes in gray matter volume and WM density in IGD. Regions consistently shown gray matter volume changes in IGD include the anterior cingulate, supplementary motor areas, cerebellum, insula, and the inferior temporal gyrus (12). There are few studies showing several brain regions that were associated with changes in WM density in IGD and therefore there is a need for studies that will select those regions that were repeatedly associated with structural changes in IGD. Except for a single study 
(25) that found an association between gray and WM changes and length of play, no inferences on causality can be drawn.

\section{Recent Studies in Young Adults and Adolescents}

Recent studies showed that adolescents with IGD had lower diffusion measures in the areas are associated with attention and control, impulse control, motor function and emotional regulation (28). IGD adolescents also showed reduced gray matter volume in regions associated with attention motor coordination working memory and perception (29) findings that are compatible with studies on gray matter volume in $\operatorname{IGD}(21,25,26)$. Moreover, gray matter volume of the anterior cingulate cortex (ACC) negatively correlated with response errors on the Stroop task (29). IGD adolescents had reduced gray matter volume in prefrontal cortex and the amygdala that correlated with Barratt Impulsivity Scale hence enabling to make an association between function (impulsivity) and structure (gray matter in the OFC and the amygdala) (27). IGD participants also showed reduced WM density in the ACC and right dorsolateral-prefrontal cortex, regions associated with executive function such as the Stroop task (30). Increased videogame play was associated with delayed development of the OCF, pallidum, putamen, hippocampus, caudate/putamen insula, and the thalamus. Furthermore, higher mean diffusivity measures in the areas of the thalamus, hippocampus, putamen, and the insula was associated with lower intelligence (31). These measures indicate an association between videogame play, intelligence, and brain development but cannot enable any causal inferences. There is also evidence for reduced WM efficiency in the frontal cortex, ACC and pallidum in IGD (32). IGD subjects had also increased WM density and decreased diffusivity in frontal fiber tracts (33). In conclusion, the studies reviewed so far present structural changes in adolescents and young adults with IGD that require replication and validation. Furthermore, these are cross-sectional studies precluding any inference on causality.

See Table 1 for resting state and structural studies of Internet and gaming disorder.

\section{Cortical Thickness}

Studies that measured cortical thickness in fMRI revealed conflicting results of increased and decreased cortical thickness in several brain regions in adolescents with IGD $(34,35)$. The cortical thickness of the OCF correlated with impaired performance on the color-word Stroop task (35). The apparent contradiction between the two studies showing increased and decreased cortical thickness seems to suggest that the changes are not robust and merit further studies.

\section{FUNCTIONAL CONNECTIVITY}

\section{Functional Connectivity at a Resting State}

Earlystudies in participants with IGD showed increased functional connectivity between regions that are associated with cognitive regulation, signal processing, and storage of relevant auditoryverbal memory processes (36). These findings are consistent with current models emphasizing the role of cortical-subcortical pathology in addiction (37). Disruption in functional connectivity in IGD may also affect motivation and reward. Smokers with IGD exhibited decreased functional connectivity with brain regions that are involved in the evaluation and expectancy of reward (38). IGD participants showed reduced connectivity in areas responsible for executive function and increased connectivity in sensorymotor brain networks (39). Lower functional connectivity in IGD affected executive control networks (40). IGD participants also showed increased volume of the caudate and nucleus accumbens as well as reduced resting state functional connectivity of dorsal prefrontal cortex (DLPFC)-caudate and OCF and the nucleus accumbens, regions associated with reward (41). Impulsivity also correlated negatively with functional connectivity between the amygdala, dorsolateral prefrontal cortex, and the OCF (42) and it was associated with alterations over the frontal-limbic connections (43). In conclusion, these are few studies with several regions that have been specifically related to drug addiction but also others that are associated with general cognitive function so more studies need to be conducted in order to select related from unrelated brain regions.

\section{Recent Studies in Adolescents}

Consistent with recent models emphasizing the role of corticalsubcortical pathology in addiction, adolescents with IGD showed reduced functional connectivity in cortical-subcortical circuits (44). IGD adolescents had also disruption in the functional connectivity in areas responsible for learning memory and executive function, processing of auditory, visual, and somatosensory stimuli and relay of sensory and motor signals (45). IGD adolescents showed decreased functional connectivity of PFC and striatal circuits areas associated with reward (46). Adolescents with IGD also showed reduced dorsal putamen functional connectivity with the posterior insula-parietal operculum (47). IGD participants had increased volumes of dorsal striatum (caudate) and ventral striatum (nucleus accumbens) (48). IGD participants also exhibited enhanced resting state functional connectivity between the anterior insula and areas that are involved in salience, craving, self-monitoring, and attention (49). Furthermore, IGD participants had stronger functional connectivity between left posterior insula and brain regions indicating reduced ability to inhibit motor responses and control over craving for Internet gaming (49). IGD participants had decreased connectivity measures between parts of the frontal cortex (50). Finally, IGD adolescents demonstrated increased functional connectivity in brain regions involved in working memory, spatial orientation and attention processing (51). In conclusion, participants with IGD showed reduced connectivity in several areas that are responsible for executive function, cognitive control, sensory processing motivation and reward. Some of these regions are common to IGD and substance use disorders but others are associated with general mechanisms of learning, memory and information processing that are not specific to IGD and substance use disorder, so a better selection is required and no inferences on causality can be drawn from present studies. See Table $\mathbf{2}$ for studies on functional connectivity in Internet and gaming disorder. 
TABLE 1 | Resting state and structural studies of Internet and gaming disorder. ${ }^{a}$

\begin{tabular}{|c|c|c|c|}
\hline Reference & Methods & Participants & Main findings and evaluations \\
\hline Park et al. (13) & $\begin{array}{l}\text { Regional cerebral metabolic rates } \\
\text { of glucose (rCMRglu) in positron- } \\
\text { emission tomography (PET) }\end{array}$ & $\begin{array}{l}\text { Eleven Internet and gaming } \\
\text { over users and nine control } \\
\text { participants }\end{array}$ & $\begin{array}{l}\text { Increased activity in the OFC, striatum, and sensory regions } \\
\text { Evaluation-a cross-sectional study with a small number of } \\
\text { participants }\end{array}$ \\
\hline Liu et al. (16) & $\begin{array}{l}\text { Regional homogeneity (ReHo) } \\
\text { measure in MRI }\end{array}$ & $\begin{array}{l}\text { Nineteen IGD college students } \\
\text { (11 males } 8 \text { females) and } 19 \\
\text { control participants }\end{array}$ & $\begin{array}{l}\text { Enhanced ReHo in the cerebellum, brainstem, right cingulate gyrus, } \\
\text { bilateral parahippocampus, right frontal lobe (rectal gyrus, inferior } \\
\text { frontal gyrus and middle frontal gyrus), left superior frontal gyrus, } \\
\text { left precuneus, right postcentral gyrus, right middle occipital gyrus, } \\
\text { right inferior temporal gyrus, left superior temporal gyrus, and middle } \\
\text { temporal gyrus } \\
\text { Evaluation - a cross-sectional study - preliminary results }\end{array}$ \\
\hline
\end{tabular}

Kuhn et al. (20) Gray matter volume measure in MRI Seventy-six frequent compared with 78 infrequent adolescent video game players (14 years old)
Higher left striatal gray matter volume negatively correlated with deliberation time on Cambridge Gambling Task Activity on the Monetary Incentive Delay task was enhanced during feedback of loss compared with no loss

Evaluation - a cross-sectional study enables to assess relationships between a cognitive task and brain's GMD

\begin{tabular}{lll}
\hline Zhou et al. (21) & Gray matter volume measure in MRI & $\begin{array}{l}\text { Eighteen Internet addicted } \\
\text { adolescents (16 males } 2 \\
\text { females) and } 15 \text { control } \\
\text { participants (13 males) }\end{array}$ \\
\hline Yuan et al. (25) & $\begin{array}{l}\text { White matter (WM) fractional } \\
\text { anisotropy (FA) changes using the } \\
\text { diffusion tensor imaging (DTI) in MRI }\end{array}$ & $\begin{array}{l}\text { Eighteen adolescents with } \\
\text { IGD (12 males) and } 18 \text { control } \\
\text { participants }\end{array}$
\end{tabular}

Lower gray matter density (GMD) in the left ACC, left PCC, left insula, and left lingual gyrus

Evaluation-a cross-sectional study - preliminary results of gray matter in IGD

Decreased gray matter volume in the bilateral DLPFC, the SMA, the OFC, the cerebellum and the left rostral ACC. Enhanced FA value of the left PLIC and reduced FA value in the WM within the right PHG Gray matter volumes of the DLPFC, rACC, SMA, and WM FA changes of the PLIC correlated with the duration of Internet addiction Evaluation-a cross-sectional study that enables evaluation of GM and WM changes over time of play

\begin{tabular}{ll}
\hline Dong et al. (12) & $\begin{array}{l}\text { Regional homogeneity }(\mathrm{ReHo}) \\
\text { measure in MRI }\end{array}$
\end{tabular}

Fifteen Internet and gaming disorder and 14 control participants

Enhanced regional homogeneity (ReHo) in the brainstem, inferior parietal lobule, left posterior cerebellum, and left middle frontal gyrus, decreased ReHo in temporal, occipital and parietal cortex Evaluation - a cross-sectional study - preliminary findings of ReHo

Han et al. (22) Gray matter volume measure in MRI Twenty IGD participants, 17 progammers

Increased impulsiveness and perseverative errors, and volume in left
thalamus gray matter, but decreased gray matter volume in inferior temporal gyri, right middle occipital gyrus, and left inferior occipital gyrus

Evaluation-a cross-sectional study preliminary findings of GM changes

Lin et al. (23) Brain WM integrity measured by diffusion tensor imaging (DTI) in MRI. Whole brain voxel-wise analysis of fractional anisotropy (FA) was performed by tract-based spatial statistics (TBSS)

\section{Seventeen Internet addiction} disorder (14 males) and 16 control adolescents

\section{Lower FA in the OFC, corpus callosum, cingulate, inferior} frontal-occipital fasciculus, and corona radiation, internal and external capsules, FA values in the left genu of the corpus callosum negatively correlated with scores on the screen for child anxiety related emotional disorders, and between FA values in the left external capsule and Young's Internet addiction scale

Evaluation-a cross-sectional study enables assessment of WM changes in relation to Internet addiction and anxiety severity

Higher fractional anisotropy (FA), in the thalamus and left PCC. Higher FA in the thalamus was associated with greater severity of Internet addiction

Evaluation-a cross-sectional study enables evaluation of changes in WM in relation to IGD severity addicted participants and 15 control participants

\begin{tabular}{|c|c|c|c|}
\hline Weng et al. (26) & $\begin{array}{l}\text { GMD and WM density changes using } \\
\text { Voxel-based morphometry (VBM) } \\
\text { analysis and tract-based spatial } \\
\text { statistics (TBSS) was reported }\end{array}$ & $\begin{array}{l}\text { Seventeen IGD participants } \\
\text { (13 females and } 4 \text { males) and } 17 \\
\text { control participants (15 females } \\
2 \text { males) }\end{array}$ & $\begin{array}{l}\text { Gray matter atrophy in the right OFC, bilateral insula, and right } \\
\text { supplementary motor area } \\
\text { Reduced FA in the right genu of corpus callosum, bilateral frontal lobe } \\
\text { WM, and right external capsule. Gray matter volumes of the right OFC } \\
\text { bilateral insula and FA values of the right external capsule positively } \\
\text { correlated with Young's Internet addiction scores } \\
\text { Evaluation-a cross-sectional study that enables evaluation of GM } \\
\text { changes in relation to IGD severity }\end{array}$ \\
\hline
\end{tabular}


TABLE 1 | Continued

\begin{tabular}{|c|c|c|c|}
\hline Reference & Methods & Participants & Main findings and evaluations \\
\hline Hong et al. (35) & Cortical thickness in MRI & $\begin{array}{l}\text { Fifteen male adolescents } \\
\text { diagnosed with Internet addiction } \\
\text { and } 15 \text { male control participants }\end{array}$ & $\begin{array}{l}\text { Decreased cortical thickness in the right lateral OFC } \\
\text { Evaluation-a cross-sectional study with preliminary results of cortical } \\
\text { thickness }\end{array}$ \\
\hline Yuan et al. (34) & Cortical thickness in MRI & $\begin{array}{l}\text { Eighteen adolescents with } \\
\text { Internet gaming disorder and } 18 \\
\text { control participants }\end{array}$ & $\begin{array}{l}\text { Increased cortical thickness in the left precentral cortex, precuneus, } \\
\text { inferior middle frontal cortex temporal and middle temporal cortices } \\
\text { Decreased cortical thicknesses of the left lateral OFC, insula, lingual gyrus, } \\
\text { the right postcentral gyrus, entorhinal cortex and inferior parietal cortex } \\
\text { Cortical thicknesses of the left precentral cortex, precuneus, and } \\
\text { lingual gyrus correlated with duration of online gaming addiction and } \\
\text { the cortical thickness of the OCF correlated with the impaired task } \\
\text { performance during the color-word Stroop task } \\
\text { Evaluation-a cross-sectional study that enables the evaluation of the } \\
\text { relationship between cortical thickness and duration of online gaming } \\
\text { and also with cognitive performance }\end{array}$ \\
\hline
\end{tabular}

Sun et al. (28) Diffusional kurtosis imaging (DKI) in the detection of gray matter diffusion
Eighteen participants with Internet gaming disorder and 21 control participants

$\begin{array}{ll}\text { Son et al. (19) } & \begin{array}{l}\text { Resting-state quantitative } \\ \text { electroencephalography (QEEG) }\end{array}\end{array}$
17 with AUD, and 25 healthy control participants
Thirty-four participants with IGD,

Lower gray matter diffusion in the right anterolateral cerebellum, right inferior and superior temporal gyri, right SMA, middle occipital gyrus, right precuneus, postcentral gyrus, right inferior frontal gyrus, left lateral lingual gyrus, left paracentral lobule, left ACC, and median cingulate cortex, bilateral fusiform gyrus, insula, PCC, and thalamus Higher GM volume in the right inferior and middle temporal gyri, and right PHG, and lower volume in the left precentral gyrus Evaluation - a cross-sectional study that measures GM diffusion-preliminary findings

IGD participants had lower absolute beta power than AUD and the healthy control group. The AUD group showed higher absolute delta power than IGD and the healthy control group. No significant correlations between the severity of IGD and QEEG activities in patients with IGD Evaluation-a cross-sectional study - enables evaluation of EEG in relation to IGD severity
Wang et al. (24) Gray matter volume measure in MRI Twenty-eight Internet participants with Internet gaming disorder and 28 control participants

Sixteen patients with Internet gaming addiction (IGD), 14 alcohol use disorder (AUD), and 15 control participants

Gray matter volume of the bilateral ACC, precuneus, SMA, SPL, left DLPFC, left insula, and bilateral cerebellum decreased in IGD participants compared with healthy control participants Gray matter volume of the ACC negatively correlated with the incongruent response errors on the Stroop Evaluation - a cross-sectional study that enabled assessment of relationship between GM changes with cognitive performance IGD and AUD participants had increased ReHo in the PCC. IGD participants showed decreased ReHo in the right superior temporal gyrus compared with AUD and control participants. Patients with AUD showed decreased ReHo in the ACC

Scores on Internet addiction severity positively correlated with ReHo in the medial frontal cortex, precuneus/PCC, and left inferior temporal cortex (ITC) among participants with IGD

Evaluation - a cross-sectional study that enabled a comparison of ReHo measures between IGD and AUD. The study enabled assessment of relationship between $\mathrm{ReHo}$ measures with IGD severity

\begin{tabular}{lll}
\hline Lin et al. (27) & GMD and WM density changes using \\
& $\begin{array}{l}\text { voxel-based morphometric analysis } \\
\text { in MRI }\end{array}$ & $\begin{array}{l}\text { Thirty-five participants with } \\
\text { Internet gaming disorder and } 36 \\
\text { control participants }\end{array}$
\end{tabular}

Takeuchi et al. (32) Diffusion tensor imaging mean diffusivity (MD)

\author{
A hundred and fourteen boys \\ and 126 girls
}

Lower GMD in the bilateral inferior frontal gyrus, left cingulate gyrus, insula, right precuneus, and right hippocampus. Lower WM density in the inferior frontal gyrus, insula, amygdala, and anterior cingulate Evaluation - a cross-sectional study with a large number of participants enables GM and WM analysis in IGD

The amount of videogame play was associated with increased MD in the left middle, inferior, and orbital frontal cortex; left pallidum; left putamen; left hippocampus; left caudate; right putamen; right insula; and thalamus in both cross-sectional and longitudinal analyses Higher MD in the areas of the left thalamus, left hippocampus, left putamen, left insula, and left Heschl gyrus was associated with lower intelligence

Evaluation - a cross-sectional study with a very large sample enables cross-sectional and longitudinal assessment of diffusion in the brain 
TABLE 1 | Continued

\begin{tabular}{|c|c|c|c|}
\hline Reference & Methods & Participants & Main findings and evaluations \\
\hline Yuan et al. (30) & $\begin{array}{l}\text { White matter (WM) integrity and } \\
\text { connectivity }\end{array}$ & $\begin{array}{l}\text { Twenty-eight IGD adolescents } \\
\text { and } 25 \text { control participants }\end{array}$ & $\begin{array}{l}\text { Reduced FA in the ACC-right dorsolateral prefrontal cortex pathways } \\
\text { in IGD } \\
\text { Evaluation-a cross-sectional study assessing WM integrity }\end{array}$ \\
\hline Zhai et al. (32) & $\begin{array}{l}\text { WM integrity measured with diffusion } \\
\text { tensor imaging (DTI) }\end{array}$ & $\begin{array}{l}\text { Sixteen right-handed } \\
\text { adolescents with IGD and } 16 \\
\text { control participants }\end{array}$ & $\begin{array}{l}\text { Reduced nodal efficiency in frontal cortex, ACC, and pallidium in IGD. } \\
\text { The global efficiency of WM network correlated with the IAT scores in IGD } \\
\text { Evaluation-a cross-sectional study assessing WM integrity and also } \\
\text { enabled assessment of the relationships between WM changes and IGD } \\
\text { severity }\end{array}$ \\
\hline Jeong et al. (33) & WM integrity and connectivity & $\begin{array}{l}\text { A hundred and eighty-one male } \\
\text { patients including } 58 \text { of IGD } \\
\text { subjects without psychiatric } \\
\text { comorbidity and } 26 \text { male control } \\
\text { subjects }\end{array}$ & $\begin{array}{l}\text { Increased FA values within forceps minor right anterior thalamic } \\
\text { radiation, right corticospinal tract, right inferior longitudinal fasciculus, } \\
\text { right cingulum to hippocampus and right inferior fronto-occipital } \\
\text { fasciculus (IFOF) decreases in RD value within forceps minor, right } \\
\text { anterior thalamic radiation, and IFOF relative to control subjects } \\
\text { Evaluation-a cross-sectional study assessing WM integrity and } \\
\text { connectivity }\end{array}$ \\
\hline Park et al. (92) & Qualitative EEG & $\begin{array}{l}\text { Sixteen adolescent males with } \\
\text { ADHD and IGD, } 15 \text { adolescent } \\
\text { males with ADHD-only, and } 15 \\
\text { healthy adolescent males }\end{array}$ & $\begin{array}{l}\text { Compared to the ADHD-only group, the ADHD + IGD group showed } \\
\text { lower relative delta power and greater relative beta power in temporal } \\
\text { regions. The relative theta power in frontal regions was higher in ADHD- } \\
\text { only group compared to HC group. Increased neuronal connectivity within } \\
\text { the parieto-occipital and temporal regions for the ADHD + IGD group } \\
\text { Evaluation-a cross-sectional study assessing qualitative EEG-low } \\
\text { localization }\end{array}$ \\
\hline Youh et al. (95) & Qualitative EEG & $\begin{array}{l}\text { Fourteen males with MDD and } \\
\text { IGD and } 15 \text { male with MDD-only }\end{array}$ & $\begin{array}{l}\text { An association between decreased interhemispheric connectivity in the } \\
\text { frontal region and vulnerability to attention problems in patients with } \\
\text { MDD and IGD } \\
\text { Interhemispheric and intrahemispheric coherence value for the alpha } \\
\text { band was significantly lower in MDD + IGD than MDD-only patients. } \\
\text { Intrahemispheric coherence values for the beta band were higher } \\
\text { in MDD + IGD than MDD-only patients. Increased intrahemisphere } \\
\text { connectivity in the frontal-temporal-parietal-occipital areas may result } \\
\text { from excessive online gaming } \\
\text { Evaluation-a cross-sectional study assessing qualitative EEG-low } \\
\text { localization }\end{array}$ \\
\hline
\end{tabular}

aStudies arranged chronologically.

DLPFC, dorsolateral prefrontal cortex; SMA, supplementary motor area; OFC, orbitofrontal cortex; ACC, anterior cingulate cortex; PLIC, posterior limb of the internal capsule; PHG, parahippocampal gyrus; PCC, posterior cingulate cortex; STG, superior temporal gyrus; MPFC, medial prefrontal cortex; AG, angular gyrus; SPL, superior parietal lobule.

\section{BRAIN ACTIVATION}

\section{Cue-Exposure Activation Studies of Videogame Urges}

Males with IGD had greater activation in the meso-corticolimbic system compared with females while playing a spaceinfringement game (52). Several frontal striatal and limbic brain regions were activated in IGD participants in fMRI (53). A longitudinal study of cue-reactivity found activation in the ACC and OCF of IGD participants over 6 weeks in fMRI (54). Gaming cues also activated regions that are associated with urges to play games (55). Furthermore, Gaming and smoking cues shared similar mechanisms of cue-induced reactivity of the frontallimbic network (56). Exposure to World of Warcraft game figures activated brain regions that were associated with cognitive, emotion and motivation-related function in IGD participants (57). IGD participants had increased activation in regions that are associated with visuospatial orientation, space, attention, mental imagery and executive function (58). IGD participants also showed attention bias to short presentations of game pictures and enhanced brain responses in the medial prefrontal cortex and the ACC (59). IGD adolescents showed activation of areas associated with visual-spatial attention and body self-awareness during ballthrowing animations simulating the experience of "disembodied state" in cyberspace $(60,61)$. In conclusion, several studies have shown a consistent pattern of brain regions that were activated in response to video playing stimuli in IGD. Secondly, studies that use tasks that simulate reward (15) enable to assess the effects of cue exposure on the brain. Finally, only a single brain-imaging study (54) followed cue-activation over time enabling an assessment of causality.

\section{Recent Activation Studies in IGD}

Internet gaming disorder participants exhibited higher cueinduced activations within the ventral and dorsal striatum compared with healthy control participants (62). There was a positive correlation between dorsal striatum activation and duration of IGD indicating a transition from ventral to dorsal striatal processing among individuals with IGD (60). Second, Internet gaming addiction appears to be associated with increased 
TABLE 2 | Studies of functional connectivity in fMRI. ${ }^{a}$

\begin{tabular}{|c|c|c|c|}
\hline Reference & Method & Participants & Main findings and evaluation \\
\hline Ding et al. (36) & $\begin{array}{l}\text { Functional } \\
\text { connectivity in fMRI }\end{array}$ & $\begin{array}{l}\text { Seventeen } \\
\text { adolescents with } \\
\text { Internet gaming } \\
\text { disorder and } 24 \\
\text { control adolescents }\end{array}$ & $\begin{array}{l}\text { Increased functional connectivity in the bilateral cerebellum posterior lobe and middle temporal } \\
\text { gyrus. Decreased connectivity in the bilateral inferior parietal lobule and right inferior temporal gyrus. } \\
\text { Connectivity with the PCC positively correlated with Internet Addiction Scores in the right precuneus, } \\
\text { PCC, thalamus, caudate, nucleus accumbens, SMA, and lingual gyrus. It negatively correlated with the } \\
\text { right cerebellum, anterior lobe and left SPL } \\
\text { Evaluation-a cross-sectional study assessing functional connectivity. Enables assessment of the } \\
\text { relationship between connectivity and IGD severity }\end{array}$ \\
\hline Hong et al. (47) & $\begin{array}{l}\text { Functional } \\
\text { connectivity in fMRI }\end{array}$ & $\begin{array}{l}\text { Twelve adolescents } \\
\text { with Internet addiction } \\
\text { and } 11 \text { control } \\
\text { participants }\end{array}$ & $\begin{array}{l}\text { Reduced functional connectivity in corticosubcortical circuits ( } 24 \% \text { with prefrontal and } \sim 27 \% \text { with } \\
\text { parietal cortex). Bilateral putamen was the most extensively involved subcortical brain region } \\
\text { Evaluation - a cross-sectional study assessing functional connectivity }\end{array}$ \\
\hline
\end{tabular}

\begin{tabular}{lll}
\hline Feng et al. (14) & $\begin{array}{l}\text { Arterial spin- } \\
\text { labeling (ASL) } \\
\text { perfusion in fMRI }\end{array}$ & Fifteen adolescents \\
& with IGA and 18 \\
& control adolescents
\end{tabular}

Higher global cerebral blood flow (CBF) in the left inferior temporal lobe/fusiform gyrus, left PHG/ perfusion in $\mathrm{FMRI}$ control adolescents amygdala, right medial frontal lobe/ACC, left and right insula, right middle temporal gyrus, right precentral gyrus, left SMA, left cingulate gyrus, and right inferior parietal lobe. Lower CBF in the left middle temporal gyrus, left middle occipital gyrus, and right cingulate gyrus Evaluation-a cross-sectional study assessing perfusion. Preliminary findings

\begin{tabular}{|c|c|c|}
\hline Wee et al. (45) & $\begin{array}{l}\text { Functional } \\
\text { connectivity in } \mathrm{fMRI}\end{array}$ & $\begin{array}{l}\text { Seventeen } \\
\text { adolescents with } \\
\text { IGD and } 16 \text { control } \\
\text { participants }\end{array}$ \\
\hline Chen et al. (38) & $\begin{array}{l}\text { Functional } \\
\text { connectivity in } \mathrm{fMRI}\end{array}$ & $\begin{array}{l}\text { Twenty-nine smokers } \\
\text { with IGD, } 22 \text { non- } \\
\text { smokers with IGD, } \\
\text { and } 30 \text { control } \\
\text { participants }\end{array}$ \\
\hline Dong et al. (40) & $\begin{array}{l}\text { Functional } \\
\text { connectivity in fMRI }\end{array}$ & $\begin{array}{l}\text { Thirty-five IGD } \\
\text { and } 36 \text { control } \\
\text { participants }\end{array}$ \\
\hline Ko et al. (42) & $\begin{array}{l}\text { GMD and } \\
\text { functional } \\
\text { connectivity in } \mathrm{fMRI}\end{array}$ & $\begin{array}{l}\text { Thirty males with } \\
\text { IGD and } 30 \text { control } \\
\text { participants }\end{array}$ \\
\hline
\end{tabular}

Disruption in the functional connectivity with the frontal, occipital, and parietal lobes

Functional connectivity with the frontal, occipital, and parietal lobes correlated with the IAD severity Evaluation-a cross-sectional study assessing functional connectivity. Enables assessment of the relationship between connectivity and IGD severity

Decreased resting state functional connectivity with posterior cingulate cortex in the right rectus gyrus. Increased resting state functional connectivity with the left middle frontal gyrus in smokers with IGA compared with non-smokers with IGA

Evaluation-a cross-sectional study assessing functional connectivity. Enables assessment of the relationship between connectivity and IGD severity.

Lower functional connectivity in executive control networks. Functional connectivity measures in executive control networks were negatively correlated with Stroop effect and positively correlated with brain activations in executive-control regions across groups

Evaluation-a cross-sectional study assessing functional connectivity. Enables assessment of the relationship between connectivity and cognitive function

Lower GMD in the bilateral amygdala and higher impulsivity. Lower functional connectivity with the left amygdala over the left DLPFC and with the right amygdala over the left DLPFC and OFC. Higher functional connectivity with the bilateral amygdala over the contralateral insula

The functional connectivity between the left amygdala and DLPFC negatively correlated with impulsivity. The functional connectivity of the right amygdala to the left DLPFC and OFC also negatively correlated with impulsivity

Evaluation - a cross-sectional study assessing functional connectivity. Enables assessment of the relationship between connectivity and impulsivity

\begin{tabular}{|c|c|c|c|}
\hline Hong et al. (47) & $\begin{array}{l}\text { Functional } \\
\text { connectivity in fMRI } \\
\text { in subdivisions of } \\
\text { striatum }\end{array}$ & $\begin{array}{l}\text { Twelve male } \\
\text { adolescents with } \\
\text { Internet gaming } \\
\text { disorder and } 11 \text { male } \\
\text { control participants }\end{array}$ & $\begin{array}{l}\text { Reduced dorsal putamen functional connectivity with the posterior insula-parietal operculum. Time } \\
\text { spent playing online games predicted significantly greater functional connectivity between the dorsa } \\
\text { putamen and bilateral primary somatosensory cortices } \\
\text { Lower functional connectivity between the dorsal putamen and bilateral sensorimotor cortices in } \\
\text { healthy control participants } \\
\text { Evaluation-a cross-sectional study assessing functional connectivity. Enables assessment of the } \\
\text { relationship between connectivity and time spent playing online }\end{array}$ \\
\hline
\end{tabular}

Wang et al. (50) Functional connectivity and voxel-mirrored homotopic Seventeen participants Decreased VMHC between the left and right superior frontal gyrus (orbital part), inferior frontal gyrus with IGD and $24 \quad$ (orbital part), middle frontal gyrus, and superior frontal gyrus connectivity $(\mathrm{VMHC})$ method

\begin{tabular}{ll}
\hline Zhang et al. (49) & Functional \\
& connectivity of the \\
& insula in fMRI
\end{tabular}
healthy control Evaluation - a cross-sectional study assessing functional connectivity participants

\section{Seventy-four young} adults with Internet gaming disorder (IGD) and 41 control participants
Enhanced functional connectivity between the anterior insula and a network of regions including ACC, putamen, angular gyrus, and precuneous. Stronger functional connectivity between the posterior insula and postcentral gyrus, pre-central gyrus, SMA, STG. IGD severity was positively associated with connectivity between the anterior insula and AG, and STG, and with connectivity between the posterior insula and STG. Duration of Internet gaming was positively associated with connectivity between the anterior insula and ACC

Evaluation - a cross-sectional study assessing functional connectivity. Enables assessment of the relationship between connectivity and duration of Internet gaming 
TABLE 2 | Continued

\begin{tabular}{|c|c|c|c|}
\hline Reference & Method & Participants & Main findings and evaluation \\
\hline Cai et al. (48) & $\begin{array}{l}\text { Functional } \\
\text { connectivity in } \mathrm{fMRI} \\
\text { in striatal nuclei } \\
\text { (caudate, putamen, } \\
\text { and nucleus } \\
\text { accumbens) volumes }\end{array}$ & $\begin{array}{l}\text { Twenty-seven } \\
\text { adolescents with } \\
\text { IGD and } 30 \text { control } \\
\text { participants }\end{array}$ & $\begin{array}{l}\text { Increased volumes of dorsal striatum (caudate) and ventral striatum (nucleus accumbens) and more } \\
\text { errors on the Stroop task. Caudate volume correlated with Stroop task performance and nucleus } \\
\text { accumbens (NAc) volume was associated with the Internet addiction test (IAT) score in the IGD group } \\
\text { Evaluation-a cross-sectional study assessing functional connectivity with the striatum. Enables } \\
\text { assessment of the relationship between volume of the striatum with cognitive performance and IGD } \\
\text { severity }\end{array}$ \\
\hline Du et al. (51) & $\begin{array}{l}\text { Functional } \\
\text { connectivity density } \\
\text { (rsFCD) in } \mathrm{fMRl}\end{array}$ & $\begin{array}{l}\text { Twenty-seven male } \\
\text { IGD adolescents and } \\
35 \text { healthy control } \\
\text { participants }\end{array}$ & $\begin{array}{l}\text { IGD adolescents exhibited higher global/long-range rsFCD in the bilateral dorsal lateral prefrontal cortex } \\
\text { (DLPFC) and the right inferior temporal cortex (ITC)/fusiform compared with healthy control participants } \\
\text { Evaluation - a cross-sectional study assessing functional connectivity }\end{array}$ \\
\hline Jin et al. (46) & $\begin{array}{l}\text { Functional } \\
\text { connectivity }\end{array}$ & $\begin{array}{l}\text { Twenty-five } \\
\text { adolescents with } \\
\text { IGD and } 21 \text { age- and } \\
\text { gender-matched } \\
\text { control participants }\end{array}$ & $\begin{array}{l}\text { Decreased functional connectivity between the insula, and temporal and occipital cortices and dorsal } \\
\text { striatum, pallidum, and thalamus in IGD. Some of those changes were associated with the severity of } \\
\text { IGD } \\
\text { Evaluation-a cross-sectional study assessing functional connectivity. Enables assessment of the } \\
\text { relationship between connectivity and IGD severity }\end{array}$ \\
\hline Wang et al. (39) & $\begin{array}{l}\text { Functional } \\
\text { connectivity }\end{array}$ & $\begin{array}{l}\text { Thirty-seven IGD } \\
\text { subjects and } 35 \\
\text { matched control } \\
\text { subjects }\end{array}$ & $\begin{array}{l}\text { Reduced connectivity in the prefrontal cortex, left posterior cingulate cortex, right amygdala, and } \\
\text { bilateral lingual gyrus, and increased functional connectivity in sensory-motor-related brain networks in } \\
\text { IGD } \\
\text { Evaluation-a cross-sectional study assessing functional connectivity }\end{array}$ \\
\hline Zhang et al. (49) & $\begin{array}{l}\text { Functional } \\
\text { connectivity of } \\
\text { insula-based } \\
\text { network }\end{array}$ & $\begin{array}{l}\text { Seventy-four young } \\
\text { adults with IGD and } \\
41 \text { age- and gender- } \\
\text { matched control } \\
\text { subjects }\end{array}$ & $\begin{array}{l}\text { Enhanced functional connectivity between the anterior insula and the ACC, putamen, angular gyrus, } \\
\text { and precuneous. Stronger functional connectivity between the posterior insula and postcentral gyrus, } \\
\text { precentral gyrus, supplemental motor area, and superior temporal gyrus (STG). IGD severity was } \\
\text { positively associated with connectivity between the anterior insula and angular gyrus, and STG, and } \\
\text { with connectivity between the posterior insula and STG. Duration of Internet gaming was positively } \\
\text { associated with connectivity between the anterior insula and ACC } \\
\text { Evaluation - a cross-sectional study assessing functional connectivity. Enables assessment of the } \\
\text { relationship between connectivity and duration of Internet gaming }\end{array}$ \\
\hline Du et al. (51) & $\begin{array}{l}\text { Functional } \\
\text { connectivity }\end{array}$ & $\begin{array}{l}\text { Twenty-seven male } \\
\text { IGD adolescents and } \\
35 \text { control } \\
\text { participants }\end{array}$ & $\begin{array}{l}\text { Enhanced functional connectivity in the bilateral dorsal lateral prefrontal cortex (DLPFC) and the right } \\
\text { inferior temporal cortex (ITC)/fusiform } \\
\text { Evaluation-a cross-sectional study assessing functional connectivity }\end{array}$ \\
\hline $\begin{array}{l}\text { Park et al. (10, } \\
43,92)\end{array}$ & $\begin{array}{l}\text { Functional } \\
\text { connectivity in fMRI }\end{array}$ & $\begin{array}{l}\text { Nineteen Internet } \\
\text { gaming disorder } \\
\text { adolescents and } 20 \\
\text { age-matched control } \\
\text { participants }\end{array}$ & $\begin{array}{l}\text { Higher impulsiveness and higher global efficiency and lower local efficiency pathological states. } \\
\text { Topological alterations were specifically attributable to inter-regional connections incident on the frontal } \\
\text { region, and the degree of impulsiveness was associated with the topological alterations over the } \\
\text { frontal-limbic connections } \\
\text { Evaluation-a cross-sectional study assessing functional connectivity }\end{array}$ \\
\hline Yuan et al. (41) & $\begin{array}{l}\text { Functional } \\
\text { connectivity in } \mathrm{fMRI}\end{array}$ & $\begin{array}{l}\text { Twenty-eight IGD } \\
\text { adolescents and } 25 \\
\text { control participants }\end{array}$ & $\begin{array}{l}\text { Reduced FA in salience network, right central executive network tracts, and between-network } \\
\text { (the ACC-right DLPFC tracts). Correlation between the effective and structural connection from } \\
\text { salience network to central executive network and the number of errors during incongruent condition } \\
\text { in Stroop task in both IGD and control participants } \\
\text { Evaluation-a cross-sectional study assessing functional connectivity. Enables assessment of the } \\
\text { relationship between connectivity and cognitive performance }\end{array}$ \\
\hline
\end{tabular}

aStudies arranged chronologically.

DLPFC, dorsolateral prefrontal cortex; SMA, supplementary motor area; OFC, orbitofrontal cortex; ACC, anterior cingulate cortex; PLIC, posterior limb of the internal capsule; PHG, parahippocampal gyrus; PCC, posterior cingulate cortex; STG, superior temporal gyrus; MPFC, medial prefrontal cortex; AG, angular gyrus; SPL, superior parietal lobule.

identification with one's avatar, indicated by high left Angular Gyrus activations in pathological Internet gamers (63). This experimental manipulation can suggest how self-identification during videogame play can affect brain mechanisms responsible for processing of auditory, visual and somatosensory modalities. Addiction to social networks was characterized by emotion regulation deficits reflected by reduced striatal activation during self-reflection compared to during ideal reflection in IGD players (63). This is an experimental manipulation of self-reflection which is related to brain activation and possibly can imply how the two interact. In conclusion, several studies have shown a consistent pattern of brain activation in response to video playing stimuli that is similar to activation of drug cues. Regions consistently activated by cue-exposure were the caudate nucleus, OCF, dorsolateral prefrontal cortex, inferior frontal cortex, anterior cingulate, PCC, para-hippocampus, and the precuneus (12). A single study (62) found an association between parts of the striatum and duration of IGD indicating long-term changes as result of play. These studies show how cue exposure can affect the brain's reward, processing of sensory information and self-reflection.

\section{Inhibitory Control Mechanisms}

Individuals with IGD display faulty inhibitory control mechanism such as impaired response inhibition on the Stroop task and 
related activity in the anterior and PCC (64). IGD participants also committed more commission errors on Go/No Go tasks and impaired response inhibition under gaming cue distraction (65). Impulsivity and response inhibition were associated with impaired function in the insula and greater activation of the frontal-striatal network in IGD (66). IGD participants also showed greater impulsivity and lower activity of motor areas while performing the Go/No Go task (67). In adolescents with IGD, there was increased activity in attention, and motor areas during No-Go trials (68). IGD participants failed to recruit frontal-basal ganglia pathway and inhibit unwanted actions on the Go-Stop paradigm (69). Furthermore, IGD participants showed higher activations when processing Internet gaming-related stimuli on a modified Stroop task in brain areas that are involved in selective attention, visual processing, working memory, and cognitive control (70).

\section{Recent Studies in IGD}

A recent study found decreased left middle and superior temporal gyrus activation during interference of socially anxious words in IGD, possibly indicating social anxiety (71). A meta-analysis concluded that individuals with IGD are more likely to exhibit impaired response inhibition (72). In conclusion, these are consistent findings that the impairment in performance of response inhibition tasks is followed by failure to recruit frontal-basal ganglia pathways and use of other brain areas during inhibition in both adolescents and adults with IGD.

\section{Reward}

Internet gaming disorder is associated with faulty decisionmaking and preference for immediate reward to long-term gains. IGD individuals subjectively experienced monetary gain and loss during the performance of a guessing task (73). IGD participants also showed increased activation in OCF in gain trials and decreased activation in the ACC during loss trials implicating enhanced reward sensitivity and decreased loss sensitivity. IGD participants also showed increased brain activity in other regions (the inferior frontal cortex, insula, ACC) and decreased activation in the caudate and PCC after continuous wins during performance on a continuous wins-and-losses task in fMRI (74). Finally, IGD participants preferred the probabilistic options to fixed ones and were faster to respond compared with control participants while performing on a probability-discounting task in fMRI (75). They also showed decreased activation in the inferior frontal gyrus and the precentral gyrus when choosing the probabilistic options than control participants. IGD participants also showed selection of risk-disadvantageous choices, and they make risky decisions more hastily and with less recruitment of regions implicated in impulse control (76). IGD adolescents had decreased reward sensitivity and they have been only sensitive to error monitoring regardless of positive feelings, such as sense of satisfaction (77). These finding imply impaired decision-making together with enhanced compensatory brain mechanisms that are consistent with impulsive decision-making.

\section{Recent Studies in IGD Participants}

A recent study showed that negative outcomes affected the covariance between risk level and activation of brain regions related to value estimation (prefrontal cortex), anticipation of rewards (Ventral Striatum), and emotional-related learning (hippocampus) which may be one of the underlying neural mechanisms of disadvantageous risky decision-making in adolescents with IGD (78). IGD participants exhibited stronger functional connectivity when selecting small and immediate gains on a delay-discounting task (79). The results indicated that IGD participants have enhanced sensitivity to reward and decreased ability to control their impulsivity effectively, which leads to suboptimal decision-making (79). Males with IGD showed decision-making deficits indicating an imbalance between hypersensitivity for reward and weaker risk experience and self-control for loss (62). A recent review has suggested that both patients with IGD and those with pathological gambling exhibit decreased loss sensitivity; enhanced reactivity to gaming and gambling cues, enhanced impulsive choice behavior aberrant reward-based learning; and no changes in cognitive flexibility (80). In conclusion, IGD adolescents showed disadvantaged increased risk-taking choices and impaired ability to control their impulses similar to other impulse control disorders. The advantage of these studies is the use of simulated decision-making tasks to assess the effects of faulty decision-making processes on brain mechanisms responsible for reward.

\section{BRAIN IMAGING STUDIES ON DOPAMINE, 5-HT AND COMORBID PSYCHIATRIC DISORDERS}

Neurotransmitters such as DA, serotonin (5-HT) play an important role in drug and alcohol dependence, mainly by mediating dopamine reward and withdrawal mechanisms $(81,82)$. Consistent with evidence in drug and AUDs which are associated with deficient dopamine reward activity (83-86) IGD participants showed reduced levels of dopamine $\mathrm{D}_{2}$ receptor availability in the striatum (87) and reduced striatal dopamine transporter (DAT) availability (88). Finally, male IGD participants showed a significant decrease in glucose metabolism in the prefrontal, temporal, and limbic regions and lower levels of $\mathrm{D}_{2}$ receptor availability in the striatum (89). The results indicate that $\mathrm{D}_{2}$ receptor-mediated dysregulation of the OCF could underlie a mechanism for loss of control and compulsive behavior in IGD. Since there is no baseline measure of dopamine levels before the addiction it is not possible to determine whether dopamine deficiency is a predisposing factor for drug and AUD disorders or IGD. Magnetic resonance spectroscopy studies showed lower levels of $\mathrm{N}$-acetylaspartate in the right frontal cortex and of choline in the medial temporal cortex in IGD participants that are similar to those of patients with attention deficit hyperactivity disorder (ADHD) and clinical depression (90). The studies so far support the evidence for deficient dopaminergic reward activity that classifies IGD as a behavioral addiction. The association between IGD and impaired self-regulation is also compatible with the model of IGD as an impulse control disorder lying within the impulsive-compulsive spectrum (1). 


\section{Recent Studies on Comorbidity of IGD with ADHD and Depression}

A recent study found that individuals with IGD showed altered PCC functional connectivity that might be dependent upon history of childhood ADHD (91). These findings suggest that altered neural networks for executive control in ADHD would be a predisposition for developing IGD. Furthermore, a study that used qualitative EGG to compare adolescents with IGD with or without ADHD found that Adolescents who show greater vulnerability to ADHD seem to continuously play Internet games to enhance attentional ability (92). Second, repetitive activation of brain reward and working memory systems during continuous gaming may result in an increase in neuronal connectivity within the parieto-occipital and temporal regions for the comorbid ADHD and IGD participants (92). Finally, a study that investigated the comorbidity of IGD with depression found that IGD participants with comorbid major depressive disorder (MDD) who performed on the Wisconsin card sorting task showed failure to suppress activity in the hippocampus during an attention demanding task, possibly as a consequence of depression (93). Patients with IGD have also shown an increased functional connectivity of several executive control brain regions that may relate to psychiatric comorbidity with ADHD and depression (94). Comorbidity of IGD with MDD was also indicated by decreased inter-hemispheric connectivity in the frontal region and vulnerability to attention problems in a study that used qualitative EEG (95). Furthermore, increased intrahemisphere connectivity in the fronto-temporo-parietooccipital areas may result from excessive online gaming. The comorbidity with depression and ADHD may also associated with dopamine deficiency in IGD. Further studies need to investigate the similarity in neurochemical and neurocognitive brain circuits in IGD and comorbid conditions such as ADHD and depression.

\section{DISCUSSION}

The studies reviewed so far show consistent findings demonstrating the resemblance between the neural mechanisms underlying substance use disorder and IGD. The behavioral addiction model argues that IGD shows the features of excessive use despite adverse consequences, withdrawal phenomena, and tolerance that characterize substance use disorders. The evidence supports the behavioral addiction model of IGD by showing structural and functional changes in the mechanisms of reward and craving (but not withdrawal) in IGD. A recent meta-analysis found a significant activation of brain regions that mediate reward (the bilateral medial frontal gyrus and the left cingulate gyrus) in IGD (96). These studies support the notion that IGD is associated with changes to the brain's reward system and mechanisms of loss of control and inhibition. There is also longitudinal evidence that pharmacological treatment with medication such as bupropion can attenuate cue reactivity in IGD (97) similar to the attenuation that occurs in nicotine-dependent users (98). IGD is associated with reduced brain's DAT density and lower dopamine $\mathrm{D}_{2}$ receptor occupancy. It seems that excessive use of the brain's dopamine reward system resembles the downregulation seen in case of drug and alcohol abuse, although in both disorder there are no baseline measures prior to the addiction precluding any inferences about causality. Finally, there is pharmacogenetic evidence that dopaminergic genes (Taq1A1 variation of dopamine $\mathrm{D}_{2}$ receptor and low activity Val158Met in the catecholamine-O-methyltransferase alleles) (99) and serotonergic genes (SS-5HTTLPR) together with personality factors may play a role in the vulnerability to IGD (100). The evidence for genetic dopaminergic vulnerability is compatible with the behavioral addiction model of IGD and consequently, IGD may be classified as a reward deficiency syndrome $(101,102)$. The evidence of genetic serotonergic vulnerability and brain imaging studies support the evidence of comorbidity of IGD with anxiety OCD and depression. Finally, playing games may be actually good for you and recent studies showed that playing computer game could improve the brain's plasticity and thus be advantageous to certain conditions such as posttraumatic stress disorder, schizophrenia, and neurodegenerative disease (103).

One of the major limitations in brain imaging studies of IGD is they are mainly cross-sectional studies without baseline measures that rely on associations between structural and functional brain changes in the brain and Internet and videogame characteristics. These associations do not provide any proof that IGD activity plays a causal role in the development of the adolescent or adult brain. There are factors that may mediate such associations such as educational, cognitive, emotional and social factors. There are methodological considerations of age (use of adolescents and students), culture (most studies were done in the Far East), and lack of comparison groups with substance use disorders and these are major limitations of the studies that were reviewed so far. Finally, very few studies looked at sex differences in cognitive and brain function in IGD.

\section{CONCLUSION}

There is an emerging evidence that IGD is associated with similar brain mechanisms responsible for substance use disorders. The brain imaging studies in IGD show similarity in brain mechanisms between IGD and substance use disorder and therefore support the classification of IGD as a behavioral addiction.

\section{AUTHOR CONTRIBUTIONS}

AW contributed substantially to the conception and design of the review.

\section{FUNDING}

AW is supported by grants from the National Institute for Psychobiology, Israel. 


\section{REFERENCES}

1. Grant JE, Potenza MN, Weinstein A, Gorelick DA. Introduction to behavioral addictions. Am J Drug Alc Abuse (2010) 36(5):233-41. doi:10.3109/0095299 0.2010 .491884

2. Young KS. Caught in the Net. New York, NY: Wiley (1998).

3. Young K. Internet addiction: diagnosis and treatment considerations. J Contemp Psychother (2009) 39(4):241-6. doi:10.1007/s10879-009-9120-x

4. Aboujaoude E. Problematic Internet use: an overview. World Psychiatry (2010) 9:85-90. doi:10.1002/j.2051-5545.2010.tb00278.x

5. Dell'Osso B, Altamura C, Allen A, Marazziti D, Hollander E. Epidemiological and clinical updates on impulse control disorders: a critical review. Eur Arch Psychiatry Clin Neurosci (2006) 256:464-75. doi:10.1007/s00406-006-0668-0

6. American Psychiatric Association. Diagnostic and Statistical Manual of Mental Disorders: DSM-5. Washington, DC: American Psychiatric Association (2013).

7. Weinstein A, Lejoyeux M. New developments on the neurobiological and pharmaco-genetic mechanisms underlying Internet and videogame addiction. Am J Addict (2015) 24(2):117-25. doi:10.1111/ajad.12110

8. Zhu Y, Zhang H, Tian M. Molecular and functional imaging of Internet addiction. Biomed Res Int (2015) 2015:378675. doi:10.1155/2015/378675

9. Kuss DJ, Griffiths MD. Internet and gaming addiction: a systematic literature review of neuroimaging studies. Brain Sci (2012) 2(3):347-74. doi:10.3390/ brainsci2030347

10. Park B, Han DH, Roh S. Neurobiological findings related to Internet use disorders. Psychiatry Clin Neurosci (2017) 71(7):467-78. doi:10.1111/pcn.12422

11. Sepede G, Tavino M, Santacroce R, Fiori F, Salerno RM, Di Giannantonio M. Functional magnetic resonance imaging of Internet addiction in young adults. World J Radiol (2016) 8(2):210-25. doi:10.4329/wjr.v8.i2.210

12. Weinstein A, Livni A, Weizman A. New developments in brain research of Internet and gaming disorder. Neurosci Biobehav Rev (2017) 75:314-30. doi:10.1016/j.neubiorev.2017.01.040

13. Park HS, Kim SH, Bang SA, Yoon EJ, Cho SS, Kim SE. Altered regional cerebral glucose metabolism in Internet game overusers: a 18F-fluorodeoxyglucose positron emission tomography study. CNS Spectr (2010) 15(3):159-66. doi:10.1017/S1092852900027437

14. Feng Q, Chen X, Sun J, Zhou Y, Sun Y, Ding W, et al. Voxel-level comparison of arterial spin-labeled perfusion magnetic resonance imaging in adolescents with Internet gaming addiction. Behav Brain Funct (2013) 9(1):33. doi:10.1186/1744-9081-9-33

15. Dong G, Huang J, Du X. Alterations in regional homogeneity of resting-state brain activity in Internet gaming addicts. Behav Brain Funct (2012) 8:41. doi:10.1186/1744-9081-8-41

16. Liu J, Gao XP, Osunde I, Li X, Zhou SK, Zheng HR, et al. Increased regional homogeneity in Internet addiction disorder a resting state functional magnetic resonance imaging study. Chin Med J (Engl) (2010) 123(14):1904-8.

17. Volkow ND, Wang GJ, Fowler JS, Tomasi D, Telang F, Baler R. Addiction: decreased reward sensitivity and increased expectation sensitivity conspire to overwhelm the brain's control circuit. Bioessays (2010) 32:748-55. doi:10.1002/bies.201000042

18. Kim H, Kim YK, Gwak AR, Lim JA, Lee JY, Jung HY, et al. Resting-state regional homogeneity as a biological marker for patients with Internet gaming disorder: a comparison with patients with alcohol use disorder and healthy controls. Prog Neuropsychopharmacol Biol Psychiatr (2015) 3(60):104-11. doi:10.1016/j.pnpbp.2015.02.004

19. Son K-L, Choi J-S, Lee J, Park SM, Lim J-A, Lee JY, et al. Neurophysiological features of Internet gaming disorder and alcohol use disorder: a resting-state EEG study. Transl Psychiatry (2015) 5:e628. doi:10.1038/tp.2015.124

20. Kuhn S, Romanowski A, Schilling C, Lorenz R, Morsen C, Seiferth N, et al. The neural basis of video gaming. Transl Psychiatry (2011) 1:e53. doi:10.1038/ tp. 2011.53

21. Zhou Y, Lin FC, Du YS, Qin LD, Zhao ZM, Xu JR, et al. Gray matter abnormalities in Internet addiction: a voxel-based morphometry study. Eur J Radiol (2011) 79(1):92-5. doi:10.1016/j.ejrad.2009.10.025

22. Han DH, Lyoo IK, Renshaw PF. Differential regional gray matter volumes in patients with on-line game addiction and professional gamers. J Psychiatr Res (2012) 46:507-15. doi:10.1016/j.jpsychires.2012.01.004

23. Lin F, Zhou Y, Du Y, Qin L, Zhao Z, Xu J, et al. Abnormal white matter integrity in adolescents with Internet addiction disorder: a tract-based spatial statistics study. PLoS One (2012) 7(1):e30253. doi:10.1371/journal. pone. 0030253

24. Wang H, Jin C, Yuan K, Shakir TM, Mao C, Niu X, et al. The alteration of gray matter volume and cognitive control in adolescents with Internet gaming disorder. Front Behav Neurosci (2015) 9:64. doi:10.3389/fnbeh.2015.00064

25. Yuan K, Qin W, Wang G, Zeng F, Zhao L, Yang X, et al. Microstructure abnormalities in adolescents with Internet addiction disorder. PLoS One (2011) 6:e20708. doi:10.1371/journal.pone.0020708

26. Weng CB, Qian RB, Fu XM, Lin B, Han XP, Niu CS, et al. Gray matter and white matter abnormalities in online game addiction. Eur J Radiol (2013) 82(8):1308-12. doi:10.1016/j.ejrad.2013.01.031

27. Lin $X$, Dong G, Wang Q, Du X. Abnormal gray matter and white matter volume in Internet gaming addicts. Addict Behav (2015) 40:137-43. doi:10.1016/j.addbeh.2014.09.010

28. Sun Y, Sun J, Zhou Y, Ding W, Chen X, Zhuang Z, et al. Assessment of in vivo microstructure alterations in gray matter using DKI in Internet gaming addiction. Behav Brain Funct (2014) 10:37. doi:10.1186/1744-9081-10-37

29. Dong G, DeVito E, Huang J, Du X. Diffusion tensor imaging reveals thalamus and posterior cingulate cortex abnormalities in Internet gaming addicts. J Psychiatr Res (2012) 46(9):1212-6. doi:10.1016/j.jpsychires.2012.05.015

30. Yuan K, Qin W, Yu D, Bi Y, Xing L, Jin C, et al. Core brain networks interactions and cognitive control in Internet gaming disorder individuals in late adolescence/early adulthood. Brain Struct Funct (2016) 221(3):1427-42. doi:10.1007/s00429-014-0982-7

31. Takeuchi H, Taki Y, Hashizume H, Asano K, Asano M, Sassa Y, et al. Impact of videogame play on the brain's microstructural properties: cross-sectional and longitudinal analyses. Mol Psychiatry (2016) 21(12):1781-9. doi:10.1038/ mp.2015.1932015

32. Zhai J, Luo L, Qiu L, Kang Y, Liu B, Yu D, et al. The topological organization of white matter network in Internet gaming disorder individuals. Brain Imaging Behav (2016):1-10. doi:10.1007/s11682-016-9652-0

33. Jeong BS, Han DH, Kim SM, Lee SW, Renshaw PF. White matter connectivity and Internet gaming disorder. Addict Biol (2016) 21(3):732-42. doi:10.1111/ adb. 12246

34. Yuan K, Cheng P, Dong T, Bi Y, Xing L, Yu D, et al. Cortical thickness abnormalities in late adolescence with online gaming addiction. PLoS One (2013) 8(1):e53055. doi:10.1371/journal.pone.0053055

35. Hong SB, Kim JW, Choi EJ, Kim HH, Suh JE, Kim CD, et al. Reduced orbitofrontal cortical thickness in male adolescents with Internet addiction. Behav Brain Funct (2013) 9:11. doi:10.1186/1744-9081-9-11

36. Ding WN, Sun JH, Sun YW, Zhou Y, Li L, Xu JR, et al. Altered default network resting-state functional connectivity in adolescents with Internet gaming addiction. PLoS One (2013) 8(3):e59902. doi:10.1371/journal.pone.0059902

37. Sutherland MT, McHugh MJ, Pariyadath V, Stein EA. Resting state functional connectivity in addiction: lessons learned and a road ahead. Neuroimage (2012) 62:2281-95. doi:10.1016/j.neuroimage.2012.01.117

38. Chen X, Wang Y, Zhou Y, Sun Y, Ding W, Zhuang Z, et al. Different resting-state functional connectivity alterations in smokers and nonsmokers with Internet gaming addiction. Biomed Res Int (2014) 2014:825787. doi:10.1155/2014/825787

39. Wang L, Wu L, Lin X, Zhang Y, Zhou H, Du X, et al. Altered brain functional networks in people with Internet gaming disorder: evidence from resting-state fMRI. Psychiatry Res (2016) 254:156-63. doi:10.1016/ j.pscychresns.2016.07.001

40. Dong G, Lin X, Potenza MN. Decreased functional connectivity in an executive control network is related to impaired executive function in Internet gaming disorder. Prog Neuropsychopharmacol Biol Psychiatry (2015) 57:76-85. doi:10.1016/j.pnpbp.2014.10.012

41. Yuan K, Yu D, Cai C, Feng D, Li Y, Bi Y, et al. Frontostriatal circuits, resting state functional connectivity and cognitive control in Internet gaming disorder. Addict Biol (2017) 22(3):813-22. doi:10.1111/adb.12348

42. Ko CH, Hsieh TJ, Wang PW, Lin WC, Yen CF, Chen CS, et al. Altered gray matter density and disrupted functional connectivity of the amygdala in adults with Internet gaming disorder. Prog Neuropsychopharmacol Biol Psychiatry (2015) 57:185-92. doi:10.1016/j.pnpbp.2014.11.003

43. Park CH, Chun JW, Cho H, Jung YC, Choi J, Kim DJ. Is the Internet gaming-addicted brain close to be in a pathological state? Addict Biol (2017) 22(1):196-205. doi:10.1111/adb.12282 
44. Hong SB, Zalesky A, Cocchi L, Fornito A, Choi EJ, Kim HH, et al. Decreased functional brain connectivity in adolescents with Internet addiction. PLoS One (2013) 8(2):e57831. doi:10.1371/journal.pone.0057831

45. Wee CY, Zhao Z, Yap PT, Wu G, Shi F, Price T, et al. Disrupted brain functional network in Internet addiction disorder: a resting-state functional magnetic resonance imaging study. PLoS One (2014) 9(9):e107306. doi:10.1371/ journal.pone.0107306

46. Jin C, Zhang T, Cai C, Bi Y, Li Y, Yu D, et al. Abnormal prefrontal cortex resting state functional connectivity and severity of Internet gaming disorder. Brain Imaging Behav (2016) 10(3):719-29. doi:10.1007/s11682-015-9439-8

47. Hong SB, Harrison BJ, Dandash O, Choi EJ, Kim SC, Kim HH, et al. A selective involvement of putamen functional connectivity in youth with Internet gaming disorder. Brain Res (2015) 1602:85-95. doi:10.1016/ j.brainres.2014.12.042

48. Cai C, Yuan K, Yin J, Feng D, Bi Y, Li Y, et al. Striatum morphometry is associated with cognitive control deficits and symptom severity in Internet gaming disorder. Brain Imaging Behav (2016) 10(1):12-20. doi:10.1007/ s11682-015-9358-8

49. Zhang JT, Yao YW, Li CS, Zang YF, Shen ZJ, Liu L, et al. Altered resting-state functional connectivity of the insula in young adults with Internet gaming disorder. Addict Biol (2016) 21(3):743-51. doi:10.1111/adb.12247

50. Wang Y, Yin Y, Sun YW, Zhou Y, Chen X, Ding WN, et al. Decreased prefrontal lobe interhemispheric functional connectivity in adolescents with Internet gaming disorder: a primary study using resting-state FMRI. PLoS One (2015) 10(3):e0118733. doi:10.1371/journal.pone.0118733

51. Du X, Yang Y, Gao P, Qi X, Du G, Zhang Y, et al. Compensatory increase of functional connectivity density in adolescents with Internet gaming disorder. Brain Imaging Behav (2016):1-9. doi:10.1007/s11682-016-9655-x

52. Hoeft F, Watson CL, Kesler SR, Bettinger KE, Reiss AL. Gender differences in the mesocorticolimbic system during computer game-play. J Psychiatr Res (2008) 42(4):253-8. doi:10.1016/j.jpsychires.2007.11.010

53. Ko CH, Liu GC, Hsiao S, Yen JY, Yang MJ, Lin WC, et al. Brain activities associated with gaming urge of online gaming addiction. J Psychiatr Res (2009) 43(7):739-47. doi:10.1016/j.jpsychires.2008.09.012

54. Han DH, Kim YS, Lee YS, Min KJ, Renshaw PF. Changes in cue-induced, prefrontal cortex activity with video-game play. Cyberpsychol Behav Soc Netw (2010) 13(6):655-61. doi:10.1089/cyber.2009.0327

55. Ko CH, Liu GC, Yen JY, Chen CY, Yen CF, Chen CS. Brain correlates of craving for online gaming under cue exposure in subjects with Internet gaming addiction and in remitted subjects. Addict Biol (2013) 18(3):559-69. doi:10.1111/j.1369-1600.2011.00405.x

56. Ko CH, Liu GC, Yen JY, Yen CF, Chen CS, Lin WC. The brain activations for both cue-induced gaming urge and smoking craving among subjects comorbid with Internet gaming addiction and nicotine dependence. J Psychiatr Res (2013) 47(4):486-93. doi:10.1016/j.jpsychires.2012.11.008

57. Sun Y, Ying H, Seetohul RM, Xuemei W, Ya Z, Qian L, et al. Brain fMRI study of crave induced by cue pictures in online game addicts (male adolescents). Behav Brain Res (2012) 233(2):563-76. doi:10.1016/j.bbr.2012.05.005

58. Liu J, Li W, Zhou S, Zhang L, Wang Z, Zhang Y, et al. Functional characteristics of the brain in college students with Internet gaming disorder. Brain Imaging Behav (2016) 10(1):60-7. doi:10.1007/s11682-015-9364-x

59. Lorenz RC, Krüger JK, Neumann B, Schott BH, Kaufmann C, Heinz A, et al. Cue reactivity and its inhibition in pathological computer game players. Addict Biol (2013) 18(1):134-46. doi:10.1111/j.1369-1600.2012.00491.x

60. Kim YR, Son JW, Lee SI, Shin CJ, Kim SK, Ju G, et al. Abnormal brain activation of adolescent Internet addict in a ball-throwing animation task: possible neural correlates of disembodiment revealed by fMRI. Prog Neuropsychopharmacol Biol Psychiatry (2012) 39(1):88-95. doi:10.1016/ j.pnpbp.2012.05.013

61. Leménager T, Dieter J, Hill H, Koopmann A, Reinhard I, Sell M, et al. Neurobiological correlates of physical self-concept and self-identification with avatars in addicted players of massively multiplayer online role-playing games (MMORPGs). Addict Behav (2014) 39(12):1789-97. doi:10.1016/ j.addbeh.2014.07.017

62. Liu L, Yip SW, Zhang JT, Wang LJ, Shen ZJ, Liu B, et al. Activation of the ventral and dorsal striatum during cue reactivity in Internet gaming disorder. Addict Biol (2017) 22(3):791-801. doi:10.1111/adb.12338

63. Leménager T, Dieter J, Hill H, Hoffmann S, Reinhard I, Beutel M, et al. Exploring the neural basis of avatar identification in pathological Internet gamers and of self-reflection in pathological social network users. J Behav Addict (2016) 5(3):485-99. doi:10.1556/2006.5.2016.048

64. Dong G, Devito EE, Du X, Cui Z. Impaired inhibitory control in 'Internet addiction disorder': a functional magnetic resonance imaging study. Psychiatr Res (2012) 203(2-3):153-8. doi:10.1016/j.pscychresns.2012.02.001

65. Liu GC, Yen JY, Chen CY, Yen CF, Chen CS, Lin WC, et al. Brain activation for response inhibition under gaming cue distraction in Internet gaming disorder. Kaohsiung J Med Sci (2014) 30(1):43-51. doi:10.1016/j.kjms.2013. 08.005

66. Ko CH, Hsieh TJ, Chen CY, Yen CF, Chen CS, Yen JY, et al. Altered brain activation during response inhibition and error processing in subjects with Internet gaming disorder: a functional magnetic imaging study. Eur Arch Psychiatry Clin Neurosci (2014) 264(8):661-72. doi:10.1007/s00406-013-0483-3

67. Chen CY, Huang MF, Yen JY, Chen CS, Liu GC, Yen CF, et al. Brain correlates of response inhibition in Internet gaming disorder. Psychiatry Clin Neurosci (2015) 69(4):201-9. doi:10.1111/pcn.12224

68. Ding WN, Sun JH, Sun YW, Chen X, Zhou Y, Zhuang ZG, et al. Trait impulsivity and impaired prefrontal impulse inhibition function in adolescents with Internet gaming addiction revealed by a Go/No-Go fMRI study. Behav Brain Funct (2014) 10:20. doi:10.1186/1744-9081-10-20

69. Li B, Friston KJ, Liu J, Liu Y, Zhang G, Cao F, et al. Impaired frontal-basal ganglia connectivity in adolescents with Internet addiction. Sci Rep (2014) 4:5027. doi:10.1038/srep05027

70. Zhang Y, Lin X, Zhou H, Xu J, Du X, Dong G. Brain activity toward gaming-related cues in Internet gaming disorder during an addiction Stroop task. Front Psychol (2016) 7:714. doi:10.3389/fpsyg.2016.00714

71. Dieter J, Hoffmann S, Mier D, Reinhard I, Beutel M, Vollstädt-Klein S, et al. The role of emotional inhibitory control in specific Internet addiction - an fMRI study. Behav Brain Res (2017) 324:1-14. doi:10.1016/j.bbr.2017.01.046

72. Argyriou E, Davison CB, Lee TT. Response inhibition and Internet gaming disorder: a meta-analysis. Addict Behav (2017) 71:54-60. doi:10.1016/ j.addbeh.2017.02.026

73. Dong G, Huang J, Du X. Enhanced reward sensitivity and decreased loss sensitivity in Internet addicts: an fMRI study during a guessing task. J Psychiatr Res (2011) 45(11):1525-9. doi:10.1016/j.jpsychires.2011.06.017

74. Dong G, Hu Y, Lin X, Lu Q. What makes Internet addicts continue playing online even when faced by severe negative consequences? Possible explanations from an fMRI study. Biol Psychol (2013) 94(2):282-9. doi:10.1016/ j.biopsycho.2013.07.009

75. Lin X, Zhou H, Dong G, Du X. Impaired risk evaluation in people with Internet gaming disorder: fMRI evidence from a probability discounting task. Prog Neuropsychopharmacol Biol Psychiatry (2015) 2:142-8. doi:10.1016/ j.pnpbp.2014.08.016

76. Dong G, Potenza MN. Risk-taking and risky decision-making in Internet gaming disorder: implications regarding online gaming in the setting of negative consequences. J Psychiatr Res (2016) 73:1-8. doi:10.1016/ j.jpsychires.2015.11.011

77. Kim JE, Son JW, Choi WH, Kim YR, Oh JH, Lee S, et al. Neural responses to various rewards and feedback in the brains of adolescent Internet addicts detected by functional magnetic resonance imaging. Psychiatry Clin Neurosci (2014) 68(6):463-70. doi:10.1111/pcn.12154

78. Qi X, Yang Y, Dai S, Gao P, Du X, Zhang Y, et al. Effects of outcome on the covariance between risk level and brain activity in adolescents with Internet gaming disorder. Neuroimage Clin (2016) 12:845-51. doi:10.1016/ j.nicl.2016.10.024

79. Wang Y, Wu L, Zhou H, Lin X, Zhang Y, Du X, et al. Impaired executive control and reward circuit in Internet gaming addicts under a delay discounting task: independent component analysis. Eur Arch Psychiatry Clin Neurosci (2017) 267(3):245-55. doi:10.1007/s00406-016-0721-6

80. Fauth-Bühler M, Mann K. Neurobiological correlates of Internet gaming disorder: similarities to pathological gambling. Addict Behav (2017) 64:349-56. doi:10.1016/j.addbeh.2015.11.004

81. Goldstein RZ, Volkow ND. Drug addiction and its underlying neurobiological basis: neuroimaging evidence for the involvement of the frontal cortex. Am J Psychiatry (2002) 159(10):1642-52. doi:10.1176/appi.ajp.159.10.1642

82. Fowler JS, Volkow ND, Kassed CA, Chang L. Imaging the addicted human brain. Sci Prac Perspect (2007) 3(2):4-16. doi:10.1151/spp07324

83. Volkow ND, Fowler JS, Wang G-J, Hitzemann R, Logan J, Schlyer D, et al. Decreased dopamine D2 receptor availability is associated with 
reduced frontal metabolism in cocaine abusers. Synapse (1993) 14:169-77. doi:10.1002/syn. 890140210

84. Volkow ND, Wang GJ, Fowler JS, Logan J, Hitzemann RJ, Ding YS, et al. Decreases in dopamine receptors but not in dopamine transporters in alcoholics. Alcohol Clin Exp Res (1996) 20:1594-8. doi:10.1111/j.1530-0277.1996. tb05936.x

85. Volkow ND, Chang L, Wang GJ, Fowler JS, Ding YS, Sedler M, et al. Low level of brain dopamine D2 receptors in methamphetamine abusers: association with metabolism in the orbitofrontal cortex. Am J Psychiatr (2001) 158(12):2015-21. doi:10.1176/appi.ajp.158.12.2015

86. Wang G-J, Volkow ND, Fowler JS, Logan J, Hitzemann RJ, Pappas NS, et al. Dopamine D2 receptor availability in opiate-dependent subjects before and after naloxone precipitated withdrawal. Neuropsychopharmacol (1997) 16:174-82. doi:10.1016/S0893-133X(96)00184-4

87. Kim SH, Baik SH, Park CS, Kim SJ, Choi SW, Kim SE. Reduced striatal dopamine D2 receptors in people with Internet addiction. Neuroreport (2011) 22(8):407-11. doi:10.1097/WNR.0b013e328346e16e

88. Hou H, Jia S, Hu S, Fan R, Sun W, Sun T, et al. Reduced striatal dopamine transporters in people with Internet addiction disorder. J Biomed Biotechnol (2012) 2010:854524. doi:10.1155/2012/854524

89. Tian M, Chen Q, Zhang Y, Du F, Hou H, Chao F, et al. PET imaging reveals brain functional changes in Internet gaming disorder. Eur J Nucl Med Mol Imaging (2014) 41(7):1388-97. doi:10.1007/s00259-014-2708-8

90. Han DH, Lee YS, Shi X, Renshaw PF. Proton magnetic resonance spectroscopy (MRS) in on-line game addiction. J Psychiatr Res (2014) 58:63-8. doi:10.1016/j.jpsychires.2014.07.007

91. Lee D, Lee J, Lee JE, Jung YC. Altered functional connectivity in default mode network in Internet gaming disorder: influence of childhood ADHD. Prog Neuropsychopharmacol Biol Psychiatry (2017) 75:135-41. doi:10.1016/ j.pnpbp.2017.02.005

92. Park JH, Hong JS, Han DH, Min KJ, Lee YS, Kee BS, et al. Comparison of QEEG findings between adolescents with attention deficit hyperactivity disorder (ADHD) without comorbidity and ADHD comorbid with Internet gaming disorder. J Korean Med Sci (2017) 32(3):514-21. doi:10.3346/jkms.2017.32.3.514

93. Han DH, Kim SM, Bae S, Renshaw PF, Anderson JS. A failure of suppression within the default mode network in depressed adolescents with compulsive Internet game play. JAffect Disord (2016) 194:57-64. doi:10.1016/ j.jad.2016.01.013

94. Han DH, Kim SM, Bae S, Renshaw PF, Anderson JS. Brain connectivity and psychiatric comorbidity in adolescents with Internet gaming disorder. Addict Biol (2017) 22(3):802-12. doi:10.1111/adb.12347

95. Youh J, Hong JS, Han DH, Chung US, Min KJ, Lee YS, et al. Comparison of electroencephalography (EEG) coherence between major depressive disorder (MDD) without comorbidity and MDD comorbid with Internet gaming disorder. J Korean Med Sci (2017) 32(7):1160-5. doi:10.3346/ jkms.2017.32.7.1160

96. Meng Y, Deng W, Wang H, Guo W, Li T. The prefrontal dysfunction in individuals with Internet gaming disorder: a meta-analysis of functional magnetic resonance imaging studies. Addict Biol (2015) 20(4):799-808. doi:10.1111/adb.12154

97. Han DH, Lee YS, Yang KC, Kim EY, Lyoo IK, Renshaw PF. Dopamine genes and reward dependence in adolescents with excessive Internet video game play. J Addict Med (2007) 1(3):133-8. doi:10.1097/ADM.0b013e31811f465f

98. Weinstein A, Greif J, Yemini Z, Lerman H, Weizman A, Even-Sapir E. Attenuation of cue-induced smoking urges and brain reward activity in successfully-treated smokers with bupropion. J Psychopharmacol (2010) 24:829-38. doi:10.1177/0269881109105456

99. Han DH, Hwang JW, Renshaw PF. Bupropion sustained release treatment decreases craving for video games and cue-induced brain activity in patients with Internet video game addiction. Exp Clin Psychopharmacol (2010) 18(4):297-304. doi:10.1037/a0020023

100. Lee Y, Han D, Yang K, Daniels M, Na C, Kee B, et al. Depression like characteristics of 5HTTLPR polymorphism and temperament in excessive Internet users. J Affect Dis (2009) 109(1):165-9. doi:10.1016/j.jad.2007.10.020

101. Blum K, Chen AL-C, Braverman ER, Comings DE, Chen TJ, Arcuri V, et al. Attention-deficit-hyperactivity disorder and reward deficiency syndrome. Neuropsychiatr Dis Treat (2008) 4(5):893-918. doi:10.2147/NDT.S2627

102. Weinstein AM, Weizman A. Emerging association between addictive gaming and attention-deficit/hyperactivity disorder. Curr Psychiatry Rep (2012) 14(5):590-7. doi:10.1007/s11920-012-0311-x

103. Kühn S, Gleich T, Lorenz RC, Lindenberger U, Gallinat J. Playing Super Mario induces structural brain plasticity: gray matter changes resulting from training with a commercial video game. Mol Psychiatry (2014) 19(2):265-71. doi:10.1038/mp.2013.120

Conflict of Interest Statement: The author declares that this research was conducted in the absence of any commercial or financial relationships that could be construed as a potential conflict of interest.

Copyright $(\odot 2017$ Weinstein. This is an open-access article distributed under the terms of the Creative Commons Attribution License (CC BY). The use, distribution or reproduction in other forums is permitted, provided the original author(s) or licensor are credited and that the original publication in this journal is cited, in accordance with accepted academic practice. No use, distribution or reproduction is permitted which does not comply with these terms. 